\title{
Microsporogenesis in Paspalum conspersum Schrad. (Virgata group) with different ploidy levels
}

\author{
L. Janke ${ }^{1}$, F.H.D. Souza ${ }^{2}$, J.F.M. Valls ${ }^{3}$ and M.S. Pagliarini ${ }^{1}$ \\ ${ }^{1}$ Laboratório de Citogenética Vegetal, \\ Departamento de Biologia Celular, Genética e Biotecnologia, \\ Universidade Estadual de Maringá, Maringá, PR, Brasil \\ ${ }^{2}$ Embrapa Pecuária Sudeste, São Carlos, SP, Brasil \\ ${ }^{3}$ Embrapa Recursos Genéticos e Biotecnologia, Brasília, DF, Brasil \\ Corresponding author: M.S. Pagliarini \\ E-mail: mspagliarini@uem.br
}

Genet. Mol. Res. 12 (4): 4948-4957 (2013)

Received February 15, 2013

Accepted July 17, 2013

Published October 24, 2013

DOI http://dx.doi.org/10.4238/2013.October.24.6

\begin{abstract}
Knowledge about the cytology and reproductive behavior of a species is indispensable for hybridization programs. This is especially true for species belonging to the genus Paspalum, among which apomixis and a wide range of ploidy levels are frequently found. Paspalum conspersum Schrad. is a robust and warm-season perennial bunchgrass native to South America. Previous studies have indicated that both tetraploid and hexaploid races exist in this species; however, only information related to tetraploids has been applied to another taxon. In this study, a cytological investigation in two Brazilian accessions collected in different regions revealed tetraploidy in the accession BRA-012823 $(2 \mathrm{n}=4 \mathrm{x}=40)$, with chromosome pairing in bivalents and normal meiosis and tetrad formation, and pentaploidy $(2 \mathrm{n}=5 \mathrm{x}=$ 50 ) in the accession BRA-022748, which presented total asynapsis. In this latter accession, 50 univalents could be scored at diakinesis. After alignment at the metaphase plate, sister chromatids segregated to the poles. Only one meiotic division (equational) occurred, and after
\end{abstract}


cytokinesis, $100 \%$ of the dyads that formed had $2 \mathrm{n}$ microspores. The meiotic behavior during microsporogenesis, which showed 10 delayed univalents to reach the metaphase plate, suggests that this accession is a recent natural hybrid constituted by a parental genome with 40 chromosomes and another with 10 chromosomes. The potential usage of these accessions in Paspalum breeding has been discussed.

Key words: Meiosis; Poaceae; Interspecific hybridization; Pentaploidy; 2n gamete

\section{INTRODUCTION}

Paspalum is a large and heterogeneous genus of the Poaceae, which includes economically important forage and turf grass cultivars. With few exceptions, Paspalum species are native to the tropical and subtropical regions of the Americas (Chase, 1929). The genus presents an immense diversity that extends from the more obvious traits, such as general morphology and growth habits, to its regions of adaptation (Burson, 1997).

In spite of the progress achieved thus far in understanding the cytological behavior of several Paspalum species, little or no information is available regarding the basic cytological composition of many other species of this genus. During the past few years, several accessions of different species with forage and turf potential have been selected from a group of 300 accessions collected in Brazil (Batista and Regitano Neto, 2000), including two accessions of Paspalum conspersum Schrad. (BRA-012823 and BRA-022748). P. conspersum, also known as "scattered paspalum", is a leafy, robust, warm season perennial bunchgrass native to South America; several cytological studies have been performed on this species (see Table 1).

To date, chromosome counts of $2 n=4 x=40$ and $2 n=6 x=60$ have been attributed to P. conspersum strains collected in Argentina, Bolivia, Brazil, and Paraguay. Accurate checking of passport data of the accessions cited by distinct authors (Table 1) confirms the conclusion of Pozzobon et al. (2000) that references to $2 n=40$ in this species can be traced to ill-identified specimens of $P$. regnellii Mez.

Tetraploids mentioned by Fernandes et al. (1974) were collected, maintained, and analyzed in Rio Grande do Sul, the southern most Brazilian State, in the framework of the S3-Cr-11 binational project, which was conducted from 1961 to 1966 to improve knowledge on the natural grasslands of Southern Brazil (Barreto, 1963). Seed samples of other accessions from the same live plant collection were sent to the United States Department of Agriculture, a project co-sponsor. These accessions were studied by Burson and Bennett (1976), at which point accessions of $P$. regnellii were mistakenly identified as $P$. conspersum, and such taxonomic uncertainties persisted for a long time, even leading Renvoize (1988) to formally designate $P$. regnellii as a synonym of $P$. conspersum.

Both species are currently accepted, and methods for their morphological differentiation have been summarized by Zuloaga and Morrone (2005). Phylogenetic distance was clarified in a recent study, where $P$. conspersum remained in the Virgata clade, while $P$. regnellii was part of a different clade, Macrophylla (Giussani et al., 2009). Valls and Oliveira (2012) did not list $P$. conspersum for Rio Grande do Sul State in their contribution for the genus for the online Flora of Brazil database. A reference to $2 \mathrm{n}=\mathrm{ca}$. 40 chromosomes for a P. conspersum strain from Bolivia (Killeen, 1990) has been revaluated. The count of $2 \mathrm{n}=4 \mathrm{x}=40$ was confirmed, but the voucher was reassigned to P. plenum Chase (Norrmann et al., 1994). 


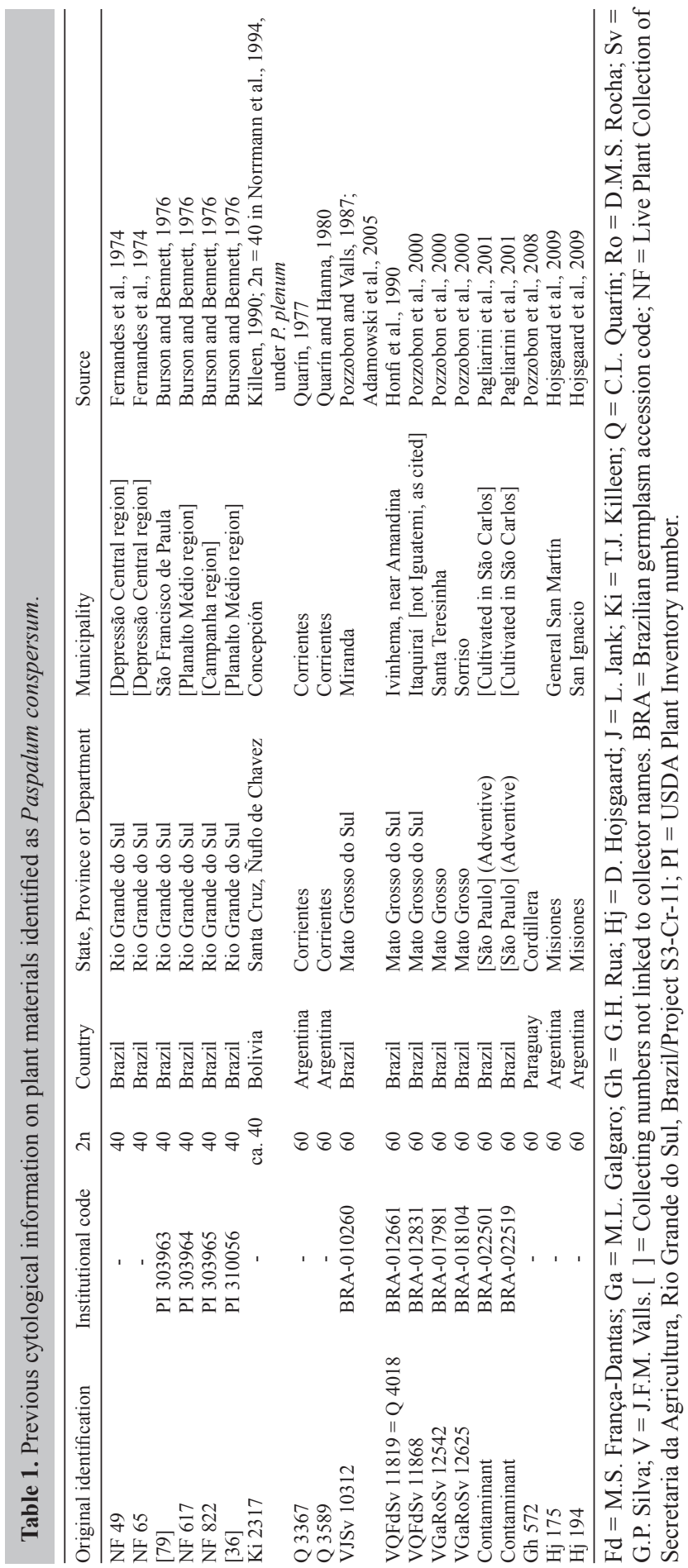


Therefore, all previous chromosome counts correctly assigned to $P$. conspersum populations correspond to $2 \mathrm{n}=6 \mathrm{x}=60$ (Table 1). They refer to plants collected in the continental Argentinian provinces of Corrientes and Misiones, in the Cordillera Department of Paraguay, as well as in Brazilian sites north of the Tropic of Capricorn. Meiotic and embryo sac studies of some of these hexaploid strains have consistently shown normal pairing as $30 \mathrm{II}$, with none or very scarce irregularities at segregation, production of normal embryo sacs, and high seed set under both open- and self-pollinated conditions, indicating a sexual, self-compatible mode of reproduction (Quarín and Hanna, 1980; Pozzobon and Valls, 1987; Pagliarini et al., 2001; Adamowski et al., 2005).

However, incorporation of additional accessions of $P$. conspersum to agronomic trials in the Paspalum gene bank of Embrapa Cattle - Southeast has focused on two peculiar strains collected in Mato Grosso do Sul State, one of which shows $2 n=4 x=40$, while the other shows $2 \mathrm{n}=5 \mathrm{x}=50$. In the present study, we report aspects of microsporogenesis of these tetraploid and pentaploid accessions and speculate on their importance and potential applications for the development of new cultivars.

\section{MATERIAL AND METHODS}

Two native Brazilian accessions of $P$. conspersum, collected in June 1988 by J.F.M. Valls, C.L. Quarín, M.S. França-Dantas, and G.P. Silva in the State of Mato Grosso do Sul, were analyzed. BRA-012823 (field number VQFdSv 11855) was originally collected at Porto Santo Antônio, near the Paraná River, in the municipality of Itaquiraí. BRA-022748 (VQFdSv 11894) was collected just north of Aral Moreira, along the frontier road that parallels the dry Brazil/Paraguay border. Both accessions are maintained in the Paspalum germplasm collection at Embrapa Cattle - Southeast, located in São Carlos, São Paulo State, Brazil.

Young inflorescences were collected and fixed in 3:1 ethyl alcohol:acetic acid for $24 \mathrm{~h}$ at room temperature, transferred to $70 \%$ aqueous alcohol solution $(\mathrm{v} / \mathrm{v})$, and stored in a freezer until evaluated. Meiocytes were obtained by squashing anthers in a drop of $1 \%$ propioniccarmine. Chromosome numbers were counted in meiocytes at diakinesis. All meiotic phases were evaluated under light microscopy and meiotic abnormalities were scored. A total of 952 and 11,151 meiocytes were evaluated in the accessions BRA-022748 and BRA-012823, respectively. Photomicrographs were taken using an Olympus microscope (CX30) and analyzed with the AnalySIS getIT software.

\section{RESULTS}

Chromosome numbers evaluated at diakinesis in both accessions revealed tetraploidy $(2 \mathrm{n}=4 \mathrm{x}=40)$ in the accession BRA-012823 and pentaploidy $(2 \mathrm{n}=5 \mathrm{x}=50)$ in the accession BRA-022748. Meiotic behavior in the tetraploid accession was quite regular (Table 2) with a few irregularities observed in chromosome segregation (Figure 1). At diakinesis, chromosomes paired exclusively as bivalents (Figure 1a).

Complete asynapsis was detected in all meiocytes of the pentaploid accession BRA022748 (Table 3). The meiosis in this accession was completely irregular. Fifty univalents were scattered throughout the cytoplasm at late diakinesis (Figure 2a and b). At the 1st meiotic metaphase, one genome with 40 univalents congregated at the equatorial plate, and the other, constituted by 10 univalents, was delayed in reaching the plate relative to the 1 st (Figure 2c). 
After a certain time, both genomes reached the equatorial plate, forming a unique and typical metaphase plate (Figure 2d). In some meiocytes, the 10 univalents were allocated in an independent metaphase plate (Figure 2e). In anaphase, sister chromatids segregated to the opposite poles (50:50) (Figure 2f), giving rise to a normal telophase (Figure $2 \mathrm{~g}$ ) that, after cytokinesis (Figure 2h), originated a dyad of microspores (Figure 2i). Only one meiotic division (equational) occurred, and two $2 \mathrm{n}$ microspores were formed.

Table 2. Meiotic behavior in the tetraploid $(2 \mathrm{n}=4 \mathrm{x}=40)$ accession of Paspalum conspersum (BRA-012823).

\begin{tabular}{lclc}
\hline Phase & Number of meiocytes & Meiotic behavior & \% abnormal meiocytes \\
\hline Diakinesis & 30 & 20 bivalents & 0.0 \\
Metaphase I & 224 & $\begin{array}{l}\text { Precocious chromosome migration to the } \\
\text { poles and non-oriented bivalents }\end{array}$ & 1.64 \\
Anaphase I & 58 & - & Micronucleus \\
Telophase I & 195 & Micronucleus & 0.0 \\
Prophase II & 152 & - & 2.56 \\
Metaphase II & 126 & - & 0.31 \\
Anaphase II & 2 & Micronucleus & 0.0 \\
Telophase II & 128 & Micronucleus & 2.34 \\
Tetrad & 236 & & 2.12 \\
Total & 1151 & & \\
\hline
\end{tabular}

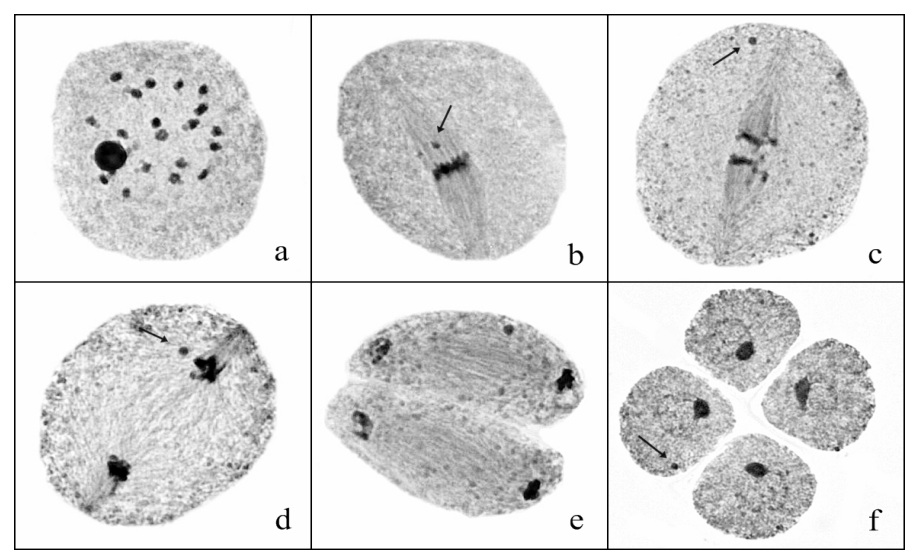

Figure 1. Aspects of microsporogenesis in the tetraploid accession of Paspalum conspersum (BRA-012823). a. Diakinesis with 20 bivalents. b. Metaphase I with precocious chromosome migration to the pole (arrow). c. Anaphase I with a non-oriented bivalent (arrow). d. Early telophase I with a micronucleus (arrow). e. Telophase II with a micronucleus. f. Tetrad with a micronucleus (arrow).

Table 3. Meiotic behavior in the pentaploid $(2 \mathrm{n}=5 \mathrm{x}=50)$ asynaptic accession of Paspalum conspersum (BRA022748).

Phase

No. of meiocytes

Diakinesis with 50 univalents

Metaphase with a non-congregated genome

Metaphase with 50 congregated univalents

Normal anaphase

Normal telophase

Normal cytokinesis after telophase

Dyad

Total

141
96
249
42
146
52
226
952

Genetics and Molecular Research 12 (4): 4948-4957 (2013) 


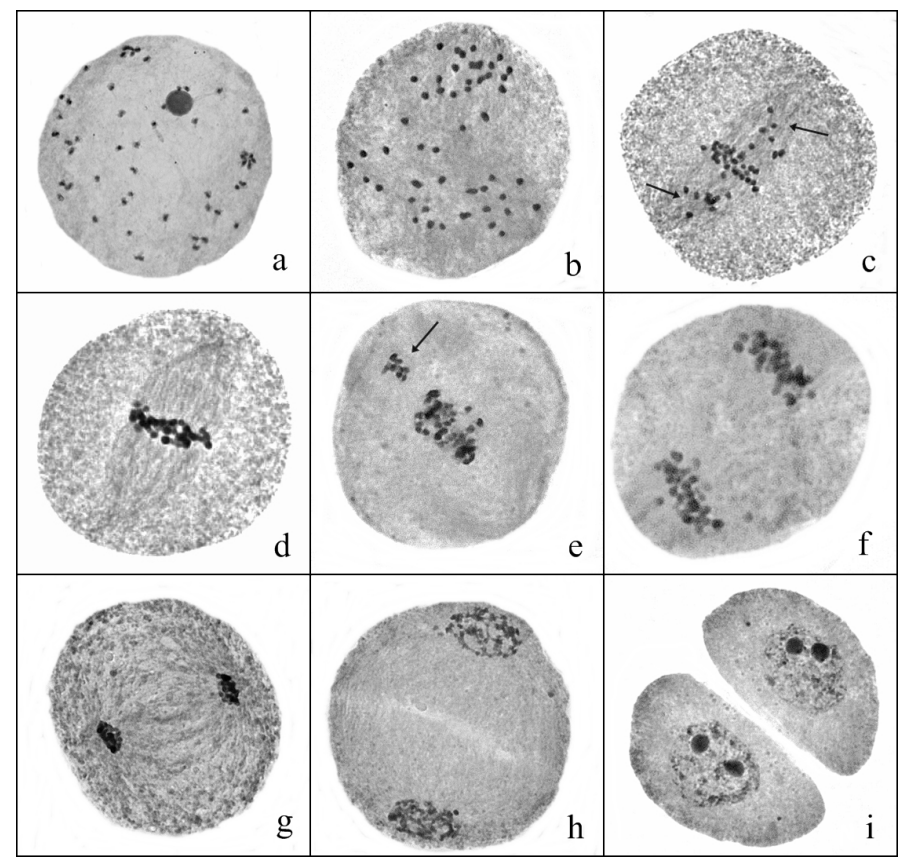

Figure 2. Aspects of microsporogenesis in the pentaploid accession of Paspalum conspersum (BRA-022748). a. Meiocyte in diakinesis with 50 univalents. b. Meiocyte in late diakinesis with 50 univalents. c. Meiocytes in metaphase showing one genome congregated at the metaphase plate (40 univalents) and the other with scattered univalents (arrows). d. Metaphase with both genomes congregating at the plate. e. Metaphase with one genome arranged in a small metaphase plate (arrow). f. Normal anaphase. g. Normal telophase. h. Cytokinesis after telophase. i. Dyad with two $2 \mathrm{n}$ microspores.

\section{DISCUSSION}

\section{Cytogenetics of $P$. conspersum}

Polyploidy, from triploidy to 16-ploidy, is found in approximately $80 \%$ of Paspalum species (Quarín, 1992), among which the most frequent chromosome set is $2 \mathrm{n}=4 \mathrm{x}=40$, and more than $70 \%$ of the listed polyploids reproduce by apomixis (Bonilla and Quarín, 1997). Previous tetraploid $(2 \mathrm{n}=4 \mathrm{x}=40)$ reports for $P$. conspersum, associated with regular meiosis and sexual reproduction (Fernandes et al., 1974; Burson and Bennett, 1976), do not, in fact, refer to this species. On the contrary, hexaploidy $(2 n=6 x=60)$ has been most commonly reported for true representatives of the species (Quarín, 1977; Quarín and Hanna, 1980; Pozzobon and Valls, 1987; Honfi et al., 1990; Pagliarini et al., 2001; Adamowski et al., 2005; Pozzobon et al., 2000, 2008; Hojsgaard et al., 2009). The 60-chromosome race of $P$. conspersum analyzed by Quarín and Hanna (1980) showed regular meiosis, with primarily bivalent pairing and a low percentage of univalents and quadrivalents. Chromosome distribution was regular at anaphase I and at anaphase II. Similar results were obtained by Pozzobon and Valls (1987), Pagliarini et al. (2001), and Adamowski et al. (2005). 
Tetraploidy and pentaploidy were here described for the 1st time for typical representatives of $P$. conspersum. Tetraploidy is the most common pattern in Paspalum, while pentaploidy has been reported in only a few species, such us $P$. minus E. Fourn. (Bonilla and Quarín, 1997), P. alcalinum Mez (Burson, 1997), P. dilatatum Poir. (Mehra and Chaudhary, 1981; Burson et al., 1991; Pozzobon et al., 2000), P. arundinellum Mez (Hojsgaard et al., 2009), and P. notatum Flüggé (Tischler and Burson, 1995).

\section{Genomes in polyploid accessions of $P$. conspersum}

Previous considerations by Burson and Bennett (1976) on genomes of tetraploid accessions of $P$. conspersum must be left aside, as they actually apply to $P$. regnellii. Dealing with a true representative of $P$. conspersum, Quarín and Hanna (1980) hypothesized that the prevalent bivalent pairing at metaphase I and the regular 30:30 chromosome distribution at anaphase I indicated that the 60-chromosome race of $P$. conspersum should be an allopolyploid with very little homology, if any, between its three genomes. The authors suggested that these could have arisen from an unreduced egg of an allotetraploid fertilized by reduced pollen of an autotetraploid species. Yet, another possible origin could be the normal fertilization of a reduced egg from an allotetraploid species by pollen of a diploid species, thus giving rise to a triploid hybrid, followed by further duplication of its chromosomes, thus producing an amphidiploid with 60 chromosomes.

The data obtained in the present study with the pentaploid accession (BRA-022748) of $P$. conspersum showed 40 univalents congregating simultaneously at the metaphase plate and 10 dispersed univalents, suggesting the presence of at least two genomes. In the pentaploid accessions of Paspalum analyzed so far, meiosis was reported to be irregular, with chromosomes associated as uni-, bi, tri-, and quadrivalents (Bonilla and Quarín, 1997; Burson, 1997). In a pentaploid plant of $P$. alcalinum, Burson (1997) suggested that it probably originated from a cross between tetraploid (unreduced egg) and diploid cytotypes (haploid sperm), where the female parent was an apomictic tetraploid and the male was a sexual diploid. In this species, members of the extra genome are present as either univalents or trivalents. In the trivalents, a haploid chromosome was synapsed with one of the members of a bivalent from the female parent. This synapsis represents homology between chromosomes of the haploid genome and a member of one genome of the tetraploid parent. In the present accession (BRA-022748) of $P$. conspersum, the absence of trivalents could indicate that the haploid genome is not homologous to the other genome.

\section{Asynapsis and hybridization}

Chromosome pairing during prophase plays a critical role in the sequence of meiotic events. The success of chromosome pairing during the early stages of the 1st meiotic division will affect the viability of the gametes formed (Visser et al., 1999). Synaptic mutants are common in several higher plant families, inclusive of Poaceae (Koduru and Rao, 1981; Singh, 2003). These mutants, which arise mostly spontaneously, may result from natural and artificial interspecific hybridization or might be induced by mutation (Ramanna and Jacobsen, 2003; Singh, 2003). Asynapsis was suggested to have occurred in a hexaploid accession of $P$. jesuiticum Parodi collected in the State of Rio Grande do Sul - Brazil (Fernandes et al., 1974), but details of meiotic behavior were not provided. Asynapsis was also reported in an apomic- 
tic tetraploid accession of $P$. secans Hitchc \& Chase (Snyder, 1961). Desynapsis, on the other hand, has been reported to occur in $P$. conjugatum P.J. Bergius, $P$. dilatatum, P. longiflorum Retz., and P. orbiculare G. Forst. (Mehra and Chaudhary, 1981).

The meiotic behavior of the new tetraploid, BRA-012823, is suggestive of a normal, sexual mode of reproduction, whereas that of the pentaploid BRA-022748 accession is typical of hybrids recently formed in nature, characterized by a dissimilar parental genome meiotic rhythm. This phenomenon has been found in one accession of P. subciliatum Chase (Adamowski et al., 1998), and is widely reported in species of the genus Brachiaria (Trin.) Griseb., which is presently merged (Shirasuna, 2012) with the circumscription of Urochloa P. Beauv. (Ricci et al., 2010). Several polyploids were formed in the past by genome duplication events occurring millions of years ago (paleopolyploids), but according to Adams and Wendel (2005), polyploidy is an active and ongoing process; the meiotic behavior of the $P$. conspersum accessions analyzed here reinforces this proposition.

\section{2n gamete formation and the breeding of Paspalum genotypes}

Equational chromatid division, such as that observed here in accession BRA-022748 of $P$. conspersum, has been observed in synaptic mutants of several species (Ramanna, 1983), including species of the Paspalum genus (Snyder, 1961; Mehra and Chaudhary, 1981; Bonilla and Quarín, 1997); dyads generating two $2 \mathrm{n}$ pollens were reported in these synaptic mutants.

The incidence of $2 \mathrm{n}$ gametes is frequent in the plant kingdom, and their occurrence has been reported in species of many families, including Poaceae (Veilleux, 1985); they result from modified meiosis affecting micro- and megasporogenesis. The absence of cytokinesis leading to $2 \mathrm{n}$ gamete formation has also been reported in several Paspalum species (Pagliarini et al., 1999).

Spontaneous polyploidy is an important phenomenon, both for evolution and for the development of new cultivars. The two main modes of polyploidization recognized are asexual polyploidization, through somatic doubling of the chromosome complement, and sexual polyploidization, through the formation and functioning of $2 \mathrm{n}$ gametes (Harlan and de Wet, 1975; Veilleux, 1985; Bretagnolle and Thompson, 1995), although the latter seems to be predominant in nature.

In the pentaploid accession of $P$. conspersum studied in the present study, $100 \%$ of the gametes presented the somatic chromosome number ( $2 \mathrm{n}$ gametes). This is unusual, since even in species or genotypes disposed to $2 \mathrm{n}$ gamete formation, the frequency of $2 \mathrm{n}$ gametes is generally variable. Veilleux (1985) listed several plant species for which the range of $2 \mathrm{n}$ pollen production varied from 0.05 to $99 \%$.

The importance of meiotic mutants to breeding has been emphasized previously, particularly with respect to the potential usefulness of $2 \mathrm{n}$ gametes formed by synaptic mutants in transmitting maximal amounts of heterozygosity. In fact, fertile $2 \mathrm{n}$ gametes were reported in synaptic mutants of different species (Ramanna, 1983). Bretagnolle and Thompson (1995) listed more than 10 abnormal mechanisms leading to 2 n gamete formation. The genetic constitution of $2 \mathrm{n}$ gametes falls into two general categories, namely, the 1st division restitution (FDR) and the 2nd division restitution (SDR) (Ramanna and Jacobsen, 2003). If the 2n gamete contains one sister chromatid of each replicated chromosome, it is an FDR $2 n$ gamete. If the $2 n$ gamete includes both sister chromatids of one of the homologous chromosomes, then it is an SDR $2 n$ gamete. The process observed in the accession BRA-022748 P. conspersum, in which 
asynapsis was accompanied by separation of the univalent sister chromatids at anaphase followed by cytokinesis after telophase, resulted in an FDR 2n gamete.

Sexual polyploidization can be successfully employed both for increasing the allelic diversity and for transferring useful traits from wild-related species into cultivated varieties. In the case of allopolyploids specifically, introgression can be achieved through recombination as a result of crossing-over between alien chromosomes, as well as from the addition of alien chromosomes (Ramanna and Jacobsen, 2003).

High efficiency $(100 \%)$ in $2 \mathrm{n}$ gamete production could be of particular importance for Paspalum breeding, for which intra- and interspecific hybridization are both desired. However, as suggested by their meiotic behavior, the pentaploid accession most likely originated from recent natural hybridization, and the genomes involved in its constitution have not yet been identified. Therefore, more studies are needed before it can be effectively used in the breeding program. Another factor impairing its use in breeding is apomixis, which is frequently associated with polyploidy (Quarín, 1992); therefore, sexual counterparts with identical ploidy levels are necessary for hybridization. Sexuality can be found among tetraploid accessions presenting regular meiosis, and was previously reported in strains that were then considered to represent P. conspersum (Fernandes et al., 1974; Burson and Bennett, 1976). Unfortunately, such data are valid for a related species, which was initially considered as another member of the same informal group Virgata, but is now understood to be phylogenetically more distant. In this context, the finding of a true $P$. conspersum strain (BRA-012823) showing the tetraploid level is promising. Although the mode of reproduction was not directly evaluated in the accession BRA012823 in the present study, its high meiotic stability suggests that it may reproduce sexually.

\section{ACKNOWLEDGMENTS}

The authors are grateful to UNIPASTO and CNPq for the financial support.

\section{REFERENCES}

Adamowski EV, Pagliarini MS and Batista LAR (1998). Chromosome elimination in Paspalum subciliatum (Notata Group). Sex. Plant Reprod. 11: 272-276.

Adamowski EV, Pagliarini MS, Bonato ABM, Batista LAR, et al. (2005). Chromosome numbers and meiotic behavior of some Paspalum accessions. Genet. Mol. Biol. 28: 773-780.

Adams KL and Wendel JF (2005). Polyploidy and genome evolution in plants. Curr. Opin. Plant Biol. 8: 135-141.

Barreto I (1963). Estudo da pastagem nativa no Rio Grande do Sul. Anu. Assoc. Gabrielense Melhoramento Renovação Pastagens 1963: 81-86.

Batista LAR and Regitano Neto A (2000). Espécies do Gênero Paspalum com Potencial Forrageiro. Doc. No. 29. Embrapa Pecuária Sudeste, São Carlos.

Bonilla JR and Quarín CL (1997). Diplosporous and aposporous apomixis in a pentaploid race of Paspalum minus. Plant Sci. 127: 97-104.

Bretagnolle F and Thompson JD (1995). Gametes with the somatic chromosome number: mechanisms of their formation and role in the evolution of autopolyploid plants. New Phytol. 129: 1-22.

Burson BL (1997). Apomixis and sexuality in some Paspalum species. Crop Sci. 37: 1347-1351.

Burson BL and Bennett HW (1976). Cytogenetics of Paspalum conspersum and its genomic relationship with yellowanthered P. dilatatum and P. malacophyllum. Can. J. Genet. Cytol. 18: 701-708.

Burson BL, Voigt PW and Evers GW (1991). Cytology, reproductive behavior, and forage potential of hexaploid dallisgrass biotypes. Crop Sci. 31: 636-641.

Chase A (1929). The North American species of Paspalum. Contrib. U. S. Nat. Herb. 28: 1-310.

Fernandes MIBM, Barreto IL, Salzano FM and Sacchet AMOF (1974). Cytological and evolutionary relationships in 
Brazilian forms of Paspalum (Gramineae). Caryologia 27: 455-465.

Giussani LM, Zuloaga FO, Quarín CL, Cota-Sánchez JH, et al. (2009). Phylogenetic relationships in the genus Paspalum (Poaceae: Panicoideae: Paniceae): An assessment of the Quadrifaria and Virgata informal groups. Syst. Bot. 34: 32-43. Harlan JR and de Wet JMJ (1975). On Ö Winge and a prayer: the origin of polyploids. Bot. Rev. 41: 361-390.

Hojsgaard D, Honfi A, Rua G and Daviña J (2009). Chromosome numbers and ploidy levels of Paspalum species from subtropical South America (Poaceae). Genet. Res. Crop Evol. 56: 533-545.

Honfi AM, Quarín CL and Valls JFM (1990). Estudios cariológicos en gramineas sudamericanas. Darwiniana 30: 87-94. Killeen TJ (1990). The grasses of Chiquitania, Santa Cruz, Bolivia. Ann. Miss. Bot. Gard. 77: 125-201.

Koduru PRK and Rao MK (1981). Cytogenetics of synaptic mutants in higher plants. Theor. Appl. Genet. 59: 197-214.

Mehra PN and Chaudhary JD (1981). Male meiosis in some grasses of the tribe Paniceae from Northeastern India 1. Genus paspalum. Cytologia 46: 265-278.

Norrmann GA, Quarín CL and Killeen TJ (1994). Chromosome numbers in Bolivian grasses (Gramineae). Ann. Miss. Bot. Gard. 81: 768-774.

Pagliarini MS, Takayama SY, Freitas PM, Carraro LR, et al. (1999). Failure of cytokinesis and $2 \mathrm{n}$ gamete formation in Brazilian accessions of Paspalum. Euphytica 108: 129-135.

Pagliarini MS, Carraro LR, De Freitas PM, Adamowski EV, et al. (2001). Cytogenetic characterization of Brazilian Paspalum accessions. Hereditas 135: 27-34.

Pozzobon MT and Valls JFM (1987). Caracterização Citogenética em Acessos de Germoplasma de Espécies Brasileiras de Paspalum (Gramineae). Anais do Encontro Internacional sobre Melhoramento Genético de Paspalum. Instituto de Zootecnia, Nova Odessa, 73-79.

Pozzobon MT, Valls JFM and Santos S (2000). Contagens cromossômicas em espécies brasileiras de Paspalum L. (Gramineae). Acta Bot. Bras. 14: 151-162.

Pozzobon MT, Machado ACC, Vaio M, Valls JFM, et al. (2008). Cytogenetic analyses in Paspalum L. reveal new diploid species and accessions. Ciênc. Rural 38: 1292-1299.

Quarín CL (1977). Recuentos cromosómicos en gramíneas de Argentina Subtropical. Hickenia 1: 73-76.

Quarín CL (1992). The nature of apomixis and its origin in panicoid grasses. Apomixis Newsl. 5: 8-15.

Quarín CL and Hanna WW (1980). Chromosome behavior, embryo sac development, and fertility of Paspalum modestum, P. boscianum, and P. conspersum. J. Hered. 71: 419-422.

Ramanna MS (1983). First division restitution gametes through fertile desynaptic mutants of potato. Euphytica 32: 337-350.

Ramanna MS and Jacobsen E (2003). Relevance of sexual polyploidization for crop improvement - a review. Euphytica 133: 3-18.

Renvoize SA (1988). Hatschbach’s Paraná Grasses. Royal Botanic Gardens, Kew.

Ricci GC, Pagliarini MS and Valle CB (2010). Genome elimination during microsporogenesis in two pentaploid accessions of Brachiaria decumbens (Poaceae). Genet. Mol. Res. 9: 2364-2371.

Shirasuna RT (2012). Urochloa. In: Jardim Botânico do Rio de Janeiro. Lista de Espécies da Flora do Brasil, Rio de Janeiro. Available at [http://floradobrasil.jbrj.gov.br/2012/FB020516]. Accessed October 29, 2012.

Singh RJ (2003). Plant Cytogenetics. 2nd edn. CRC Press, Boca Raton.

Snyder LA (1961). Asyndesis and meiotic non-reduction in microsporogenesis of apomictic Paspalum secans. Cytologia 26: 50-61.

Tischler CR and Burson BL (1995). Evaluating different bahiagrass cytotypes for heat tolerance and leaf epicuticular wax content. Euphytica 84: 229-235.

Valls JFM and Oliveira RC (2012). Paspalum. In: Jardim Botânico do Rio de Janeiro. Lista de Espécies da Flora do Brasil, Rio de Janeiro. Available at [http://floradobrasil.jbrj.gov.br/2012/FB013476]. Accessed October 29, 2012.

Veilleux R (1985). Diploid and polyploid gametes in crop plants: mechanisms of formation and utilization in plant breeding. Plant Breed. Rev. 3: 253-288.

Visser NC, Spies JJ and Venter HJT (1999). The presence of synaptic and chromosome disjunction mutants in Cenchrus ciliaris Poaceae: Paniceae. Bothalia 29: 327-334.

Zuloaga FO and Morrone O (2005). Revisión de las Especies de Paspalum para América del Sur Austral. Missouri Botanical Garden Press, Saint Louis. 